\title{
On the attribution of stratospheric ozone and temperature changes to changes in ozone-depleting substances and well-mixed greenhouse
} gases

\author{
T. G. Shepherd and A. I. Jonsson \\ Department of Physics, University of Toronto, 60 St. George Street, Toronto, Ontario, M5S 1A7, Canada \\ Received: 15 August 2007 - Published in Atmos. Chem. Phys. Discuss.: 21 August 2007 \\ Revised: 30 October 2007 - Accepted: 13 February 2008 - Published: 12 March 2008
}

\begin{abstract}
The vertical profile of global-mean stratospheric temperature changes has traditionally represented an important diagnostic for the attribution of the cooling effects of stratospheric ozone depletion and $\mathrm{CO}_{2}$ increases. However, $\mathrm{CO}_{2}$-induced cooling alters ozone abundance by perturbing ozone chemistry, thereby coupling the stratospheric ozone and temperature responses to changes in $\mathrm{CO}_{2}$ and ozonedepleting substances (ODSs). Here we untangle the ozonetemperature coupling and show that the attribution of globalmean stratospheric temperature changes to $\mathrm{CO}_{2}$ and ODS changes (which are the true anthropogenic forcing agents) can be quite different from the traditional attribution to $\mathrm{CO}_{2}$ and ozone changes. The significance of these effects is quantified empirically using simulations from a three-dimensional chemistry-climate model. The results confirm the essential validity of the traditional approach in attributing changes during the past period of rapid ODS increases, although we find that about $10 \%$ of the upper stratospheric ozone decrease from ODS increases over the period 1975-1995 was offset by the increase in $\mathrm{CO}_{2}$, and the $\mathrm{CO}_{2}$-induced cooling in the upper stratosphere has been somewhat overestimated. When considering ozone recovery, however, the ozone-temperature coupling is a first-order effect; fully $2 / 5$ of the upper stratospheric ozone increase projected to occur from 2010-2040 is attributable to $\mathrm{CO}_{2}$ increases. Thus, it has now become necessary to base attribution of global-mean stratospheric temperature changes on $\mathrm{CO}_{2}$ and ODS changes rather than on $\mathrm{CO}_{2}$ and ozone changes.
\end{abstract}

Correspondence to: T. G. Shepherd

(tgs@atmosp.physics.utoronto.ca)

\section{Introduction}

The attribution of changes in atmospheric conditions to different anthropogenic forcings is an important problem in climate science. In the middle atmosphere, the global mean temperature is, to good approximation, in radiative balance (see e.g. Fig. 5 of Fomichev et al., 2002) and is thus controlled overwhelmingly by radiative processes; dynamical effects on temperature, such as those resulting from the Brewer-Dobson circulation, may be important over specific latitude bands but approximately cancel out in the global mean. This feature makes global-mean temperature a valuable diagnostic for attribution, and the vertical profile of its long-term changes has been much studied (e.g. Ramaswamy et al., 2001; Shine et al., 2003) as a key fingerprint of stratospheric ozone depletion.

Observations show that global-mean stratospheric cooling has occurred since 1979 (the beginning of the continuous satellite record), preferentially in the lower and the upper stratosphere. Numerous studies have shown that the cooling of the lower stratosphere has been mainly due to ozone depletion, while the cooling of the upper stratosphere has been due to both ozone depletion and $\mathrm{CO}_{2}$ increases, roughly in equal measure (see Chap. 5 of WMO, 2007). But there is something fundamentally incorrect about this way of presenting the results. Stratospheric ozone is not an anthropogenic forcing agent, rather it is (like water vapour) an internal property of the atmosphere. For example, cooling of the upper stratosphere increases ozone abundance, by slowing ozone destruction rates, and the increased ozone abundance offsets some of the cooling (e.g. Haigh and Pyle, 1982; Jonsson et al., 2004). This ozone-temperature feedback has, therefore, mitigated the upper stratospheric cooling that would otherwise have occurred from the $\mathrm{CO}_{2}$ changes alone.

Published by Copernicus Publications on behalf of the European Geosciences Union. 
The primary anthropogenic forcing agents for past stratospheric ozone and temperature changes are ozone-depleting substances (ODSs) and $\mathrm{CO}_{2}$ (Chaps. 5 and 6 of WMO, 2007). Because of the ozone-temperature feedback, the upper stratospheric ozone depletion due to ODSs has been partially masked by $\mathrm{CO}_{2}$-induced ozone increases. It follows that using the observed ozone decreases to attribute globalmean temperature changes must underestimate the cooling due to ODSs (via ozone depletion), and overestimate the cooling due to $\mathrm{CO}_{2}$ increases. While these considerations must surely be well known, they seem not to have been pointed out explicitly, nor the limitations of ozone-based attribution discussed - let alone quantified. However, this issue will become increasingly important in the future, as the ODS loading in the stratosphere begins to slowly decline and the attribution of stratospheric temperature changes will need to be more accurately performed as a diagnostic of ozone recovery from the effects of ODSs.

Beyond making the above statements, the purpose of this paper is two-fold: first, to demonstrate that it is possible to untangle the ozone-temperature feedback and separately attribute the ozone and temperature changes due to ODS and $\mathrm{CO}_{2}$ changes (at least for small ozone and temperature changes), contrasting them with what would be inferred from the "traditional" approach (e.g. WMO, 2007) based on ozone and $\mathrm{CO}_{2}$ (Sect. 2); and, second, to use results from a threedimensional chemistry-climate model to provide an empirical estimation of the ODS- $\mathrm{CO}_{2}$ attribution of past and future changes (Sect. 3). We note that stratospheric temperature and ozone are affected also by other long-term changes in the atmosphere, e.g. by changes in $\mathrm{CH}_{4}, \mathrm{H}_{2} \mathrm{O}$ and $\mathrm{N}_{2} \mathrm{O}$. However, this does not undermine our basic point about attribution. Moreover, for the purpose of this paper such effects can generally be disregarded as second order effects. Some justification for this assumption and limitations to our methodology are given in Sect. 4.

\section{Untangling the ozone-temperature feedback: attribu- tion of stratospheric ozone and temperature changes to changes in ODSs and $\mathrm{CO}_{2}$}

We present a heuristic analysis of the ozone-temperature feedback and its implications for attribution. In this analysis we do not consider heterogeneous chemistry, which means that this analysis is not relevant in the lowest part of the stratosphere. Nor do we consider changes in forcings other than $\mathrm{CO}_{2}$ and ODSs, in order to simplify the analysis. Since we are interested in long-term (i.e. decadal or longer) changes, we may assume steady-state conditions. Furthermore as we are, for the most part, interested in small perturbations (e.g. at the $10 \%$ level), we may neglect nonlinearities in the coefficients to a first approximation. Thus, all variables represent perturbations to some reference state. While the small-perturbation assumption is violated for the
ODS perturbations, this does not compromise the analysis since the role of ODSs in the temperature dependence of the gas-phase chemical ozone loss is small (see e.g. Fig. 1.12 of IPCC/TEAP, 2005).

Stratospheric temperature responds to $\mathrm{O}_{3}$ and $\mathrm{CO}_{2}$ perturbations, which we can represent as follows:

$\frac{\partial(\Delta T)}{\partial t}=0=a \Delta \mathrm{O}_{3}-b \Delta \mathrm{CO}_{2}-c \Delta T$.

The signs have been chosen such that $a, b$ and $c$ are all positive. The damping term represents radiative relaxation to the reference state (based on the background ozone and $\mathrm{CO}_{2}$ distributions). Thus, ozone and $\mathrm{CO}_{2}$ perturbations pull the temperature away from the reference state - increasing ozone warms the stratosphere by absorption of solar radiation, while increasing $\mathrm{CO}_{2}$ cools it by infrared emission. At the same time, ozone responds to temperature and ODSs, which we can represent as follows:

$\frac{\partial\left(\Delta \mathrm{O}_{3}\right)}{\partial t}=0=-d \Delta \mathrm{ODS}-e \Delta T-f \Delta \mathrm{O}_{3}$.

Once again the signs have been chosen such that $d, e$ and $f$ are all positive, and the damping term represents photochemical relaxation to the reference state. Thus, ODS and temperature perturbations pull ozone away from the reference state - increasing ODSs decreases stratospheric ozone by increasing the efficiency of those catalytic ozone-destruction cycles involving ODSs, while increasing temperature decreases it by increasing the efficiency of all catalytic ozone-destruction cycles.

The ozone-temperature feedback is represented by the coefficient $e$. If $e=0$, then (2) implies $\Delta \mathrm{O}_{3}=-(d / f) \Delta \mathrm{ODS}$; in this case, ozone responds exclusively to ODSs and, in (1), affects temperature completely independently of $\mathrm{CO}_{2}$, i.e. their effects are superposable. This is the assumption made in all current attribution studies (e.g. Shine et al., 2003; WMO, 2007). So the question at hand is, how important are the effects that come from having $e \neq 0$ ?

From (1) and (2) we obtain the relations

$$
\begin{aligned}
& (a e+c f) \Delta \mathrm{O}_{3}=b e \Delta \mathrm{CO}_{2}-c d \Delta \mathrm{ODS}, \\
& (a e+c f) \Delta T=-a d \Delta \mathrm{ODS}-b f \Delta \mathrm{CO}_{2} .
\end{aligned}
$$

This - rather than (1)-(2) - is the more informative way to write the equations, since ozone and temperature are the internal variables which respond to the external forcings $\mathrm{CO}_{2}$ and ODS. Equation (3) shows that ozone increases from $\mathrm{CO}_{2}$ increases (through cooling) and decreases from ODS increases, while (4) shows that temperature decreases from ODS increases (through ozone loss) and from $\mathrm{CO}_{2}$ increases. So these relations contain the key effects that we are interested in. And they are moreover linear; the effects of $\mathrm{CO}_{2}$ and ODSs are superposable. So this way of writing things untangles the ozone-temperature feedback, making attribution clear-cut (in the limit of small perturbations). 
We may note already that the effect of having $e \neq 0$ is to $i n-$ crease the magnitude of the coefficient on the left-hand side of both (3) and (4), which means that the ozone-temperature feedback damps both the ozone response to ODSs (because the decrease in ozone lowers the temperature, which increases ozone) and the temperature response to $\mathrm{CO}_{2}$ (because the lower temperature increases ozone, which increases temperature). Moreover the magnitude of the damping effect is the same for both ozone and temperature.

Now, let us consider the temperature response to a $\mathrm{CO}_{2}$ change, which from (4) is given by

$\Delta T_{\mathrm{CO}_{2}}=-\frac{b f}{a e+c f} \Delta \mathrm{CO}_{2}$.

We write $\Delta T_{\mathrm{CO}_{2}}^{R}$ as the "radiative" estimate, with no ozonetemperature feedback (i.e. with $e=0$ ), namely

$\Delta T_{\mathrm{CO}_{2}}^{R}=-\frac{b}{c} \Delta \mathrm{CO}_{2}$

Equation (6) is also derivable directly from (1) by setting $\Delta \mathrm{O}_{3}=0$. It follows that

$\frac{\Delta T_{\mathrm{CO}_{2}}}{\Delta T_{\mathrm{CO}_{2}}^{R}}=\frac{1}{1+(\text { ae/cf })}$.

Thus, the temperature response to $\mathrm{CO}_{2}$ is overestimated if the ozone-temperature feedback is not included. The physical interpretation of this result is that the temperature response to $\mathrm{CO}_{2}$ changes is damped by the ozone-temperature feedback, as noted above. By comparing non-interactive and interactive responses to doubled $\mathrm{CO}_{2}$ using the Canadian Middle Atmosphere Model, Jonsson et al. (2004) found that the overestimate can be as large as $30 \%$ in the upper stratosphere.

Now consider the temperature response to an ODS change, which from (4) is given by

$\Delta T_{\mathrm{ODS}}=-\frac{a d}{(a e+c f)} \Delta \mathrm{ODS}$.

As noted above, however, the current practice is to diagnose the temperature change due to ozone changes, with the implicit assumption that the latter are attributable to the ODS changes. We write $\Delta T_{\mathrm{O}_{3}}$ for this ozone-based "estimate" of the ODS-induced temperature change, which from (1) is given by

$\Delta T_{\mathrm{O}_{3}}=\frac{a}{c} \Delta \mathrm{O}_{3}$.

Using (3) this can be expressed as

$\Delta T_{\mathrm{O}_{3}}=\frac{a / c}{(a e+c f)}\left(\right.$ be $\left.\Delta \mathrm{CO}_{2}-c d \Delta \mathrm{ODS}\right)$.

It follows that

$$
\frac{\Delta T_{\mathrm{ODS}}}{\Delta T_{\mathrm{O}_{3}}}=-\frac{c d \Delta \mathrm{ODS}}{\left(\text { be } \Delta \mathrm{CO}_{2}-c d \Delta \mathrm{ODS}\right)}=\frac{1}{1-\frac{b e}{c d} \frac{\Delta \mathrm{CO}_{2}}{\Delta \mathrm{ODS}}} .
$$

We see that the temperature response to ODS-induced ozone loss is currently underestimated. The physical interpretation of this result is that using observed ozone changes underestimates the effects of ODSs, because the increase in $\mathrm{CO}_{2}$ has mitigated some of the ozone loss due to ODSs. In other words, ozone would have decreased more from ODSs (and led to more cooling) had it not been for the $\mathrm{CO}_{2}$ increase. And since there is a minus sign in the denominator of (11), unlike in the case of (7), the underestimate could potentially be quite large.

On the other hand, as ODS abundances begin to decrease in the future, then relative to current conditions $\triangle \mathrm{ODS}<0$ and (11) will become less than unity rather than greater than unity. In that case, estimating the temperature changes from the observed ozone changes through $\Delta T_{\mathrm{O}_{3}}$ will overestimate the effect of ODSs (basically because part of the ozone increase will be the result of the $\mathrm{CO}_{2}$ increase rather than the ODS decrease). So quantifying the effects properly will be an important aspect of the attribution of ozone recovery from the effects of ODSs.

It was noted above, in the discussion below (11), that the $\mathrm{CO}_{2}$ increase has masked some fraction of the ozone depletion that would have occurred from the ODS increase. We can also quantify this effect. From (3) we have

$\Delta \mathrm{O}_{3}=\frac{\text { be } \Delta \mathrm{CO}_{2}-c d \Delta \mathrm{ODS}}{(a e+c f)}$.

On the other hand, the ozone change that is actually attributable to the ODS change, which we denote by $\Delta \mathrm{O}_{3}$ ODS, is from (3) given by

$\Delta \mathrm{O}_{3}$ ODS $=-\frac{c d}{(a e+c f)} \Delta \mathrm{ODS}$.

The ratio of the two is

$\frac{\Delta \mathrm{O}_{3} \mathrm{ODS}}{\Delta \mathrm{O}_{3}}=-\frac{c d \Delta \mathrm{ODS}}{\left(\text { be } \Delta \mathrm{CO}_{2}-c d \Delta \mathrm{ODS}\right)}=\frac{1}{1-\frac{b e}{c d} \frac{\Delta \mathrm{CO}_{2}}{\Delta \mathrm{ODS}}}$,

which is exactly the same ratio as (11). Thus, this suggests that the ODS-induced ozone decrease in the upper stratosphere has been partially masked by the $\mathrm{CO}_{2}$ increase. Moreover, we can anticipate that in the future, as ODS levels slowly decline, the observed ozone increase will be considerably greater than that attributable to the ODS recovery.

\section{An empirical estimation of the $\mathrm{ODS}-\mathrm{CO}_{2}$ attribution of stratospheric ozone and temperature changes}

In principle, it should be possible to calculate the various coefficients in Sect. 2 as a function of latitude, altitude, and season, to provide a theoretical determination of the significance of the ozone-temperature feedback for attribution of stratospheric ozone and temperature changes. However there are technical complications because of non-local coupling within each column of atmosphere. Instead, we here provide 

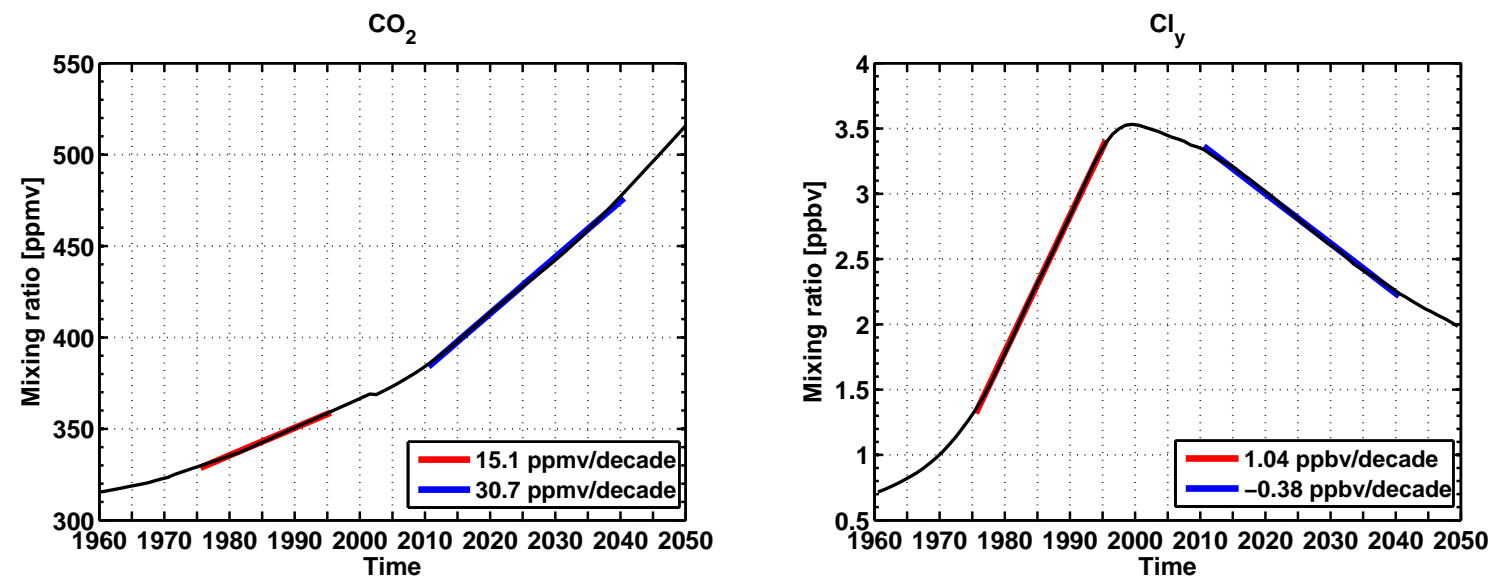

Fig. 1. Annual and global mean timeseries of $\mathrm{CO}_{2}$, and of $\mathrm{Cl}_{\mathrm{y}}$ (total inorganic chlorine) at $2 \mathrm{hPa}$, from CMAM. We use upper stratospheric $\mathrm{Cl}_{\mathrm{y}}$ as a proxy for ODSs in this analysis since there is a time delay of several years between surface ODS values and $\mathrm{Cl}_{\mathrm{y}}$ levels in the upper stratosphere. Also, bromine is mainly important for heterogeneous chemistry. (In any case, the bromine source gases are held constant in these simulations.) The thick red and blue lines indicate linear fits to the periods 1975-1995 and 2010-2040, respectively.
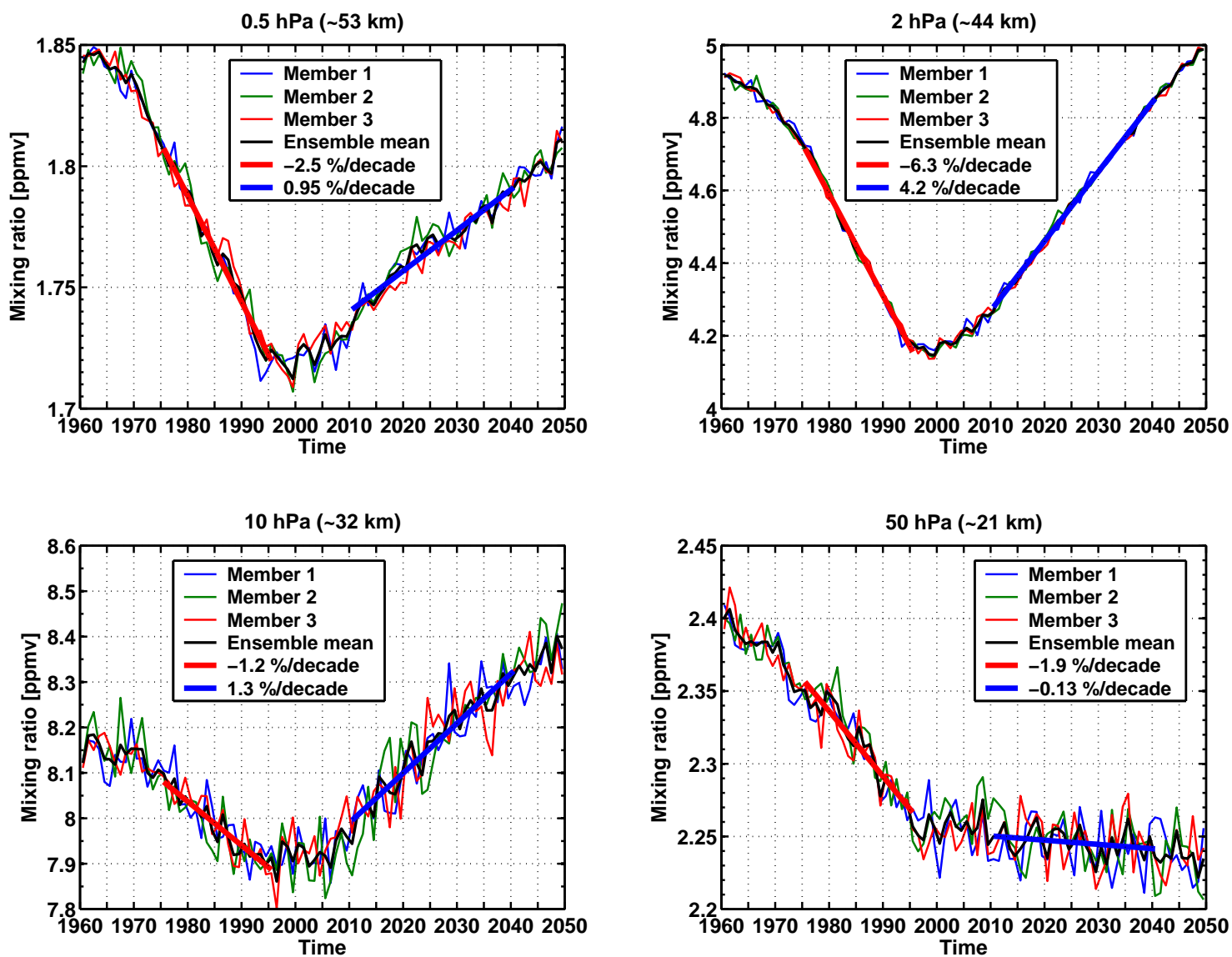

Fig. 2. Annual and global mean timeseries of ozone at $0.5,2,10$, and $50 \mathrm{hPa}$ (corresponding log-pressure heights are indicated), from CMAM. The thin coloured lines indicate results from three individual ensemble members, the black line shows the ensemble average results, and the thick red and blue lines indicate linear fits to the ensemble mean data for the periods 1975-1995 and 2010-2040, respectively. 

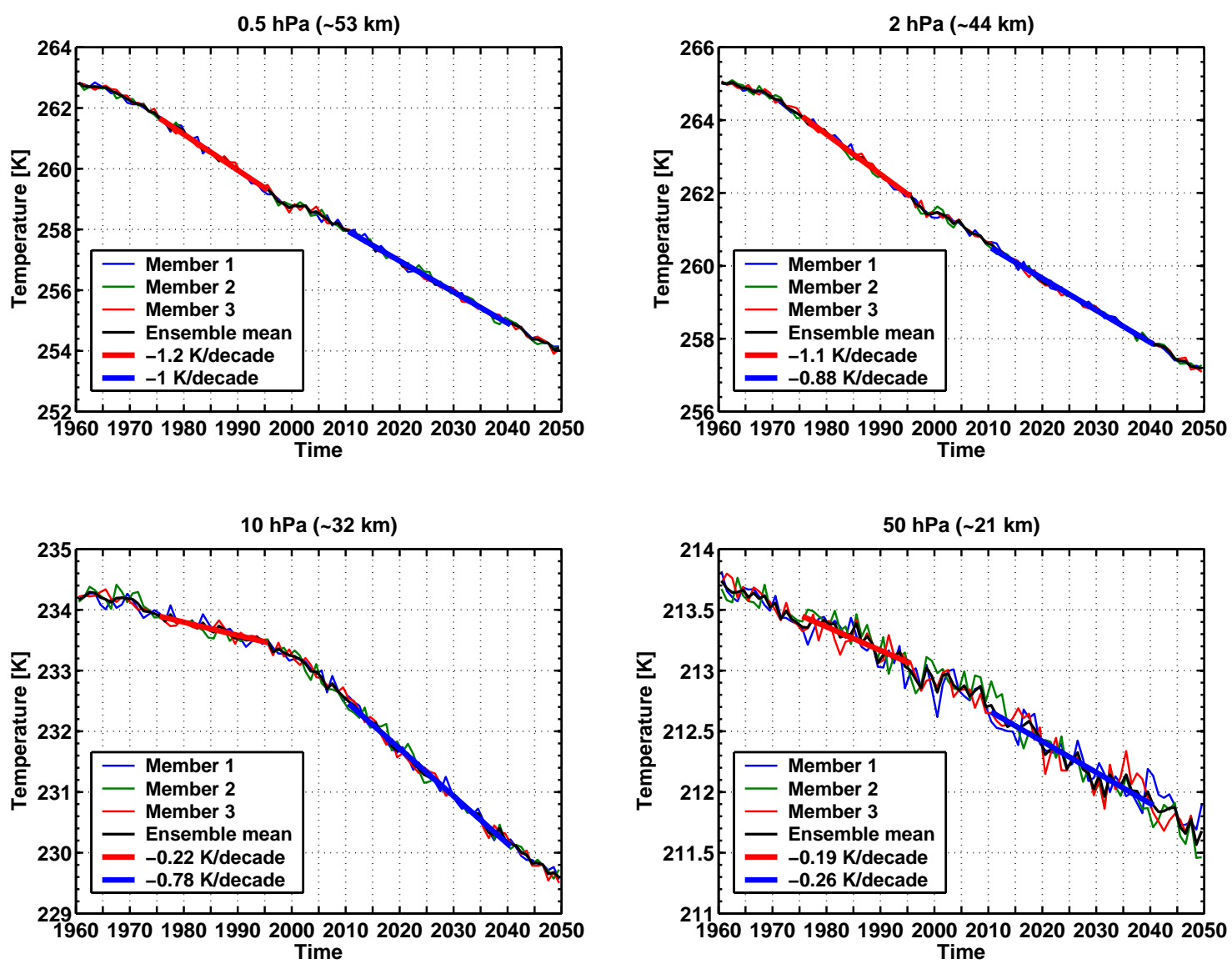

Fig. 3. Same as Fig. 2 but for temperature.

a simple empirical estimate of the effect, using simulations from the Canadian Middle Atmosphere Model (CMAM) - a fully interactive three-dimensional chemistry climate model (de Grandpré et al., 2000) - and exploiting the strong contrast between the past and future time dependence of the ODSs.

Figure 1 shows the $\mathrm{CO}_{2}$ and ODS timeseries in the upper stratosphere from CMAM simulations which follow the SPARC CCMVal "REF2" scenario described in Eyring et al. (2005). The behaviour of a number of chemistry climate models, including CMAM, under this scenario is described in Eyring et al. (2007). As can be seen from Fig. 1, both $\mathrm{CO}_{2}$ and ODSs evolve roughly linearly with time in both the past and the future, with the $\mathrm{CO}_{2}$ trend increasing in the future and the ODS trend changing sign according to the assumed scenarios. (The inflection point in $\mathrm{CO}_{2}$ in 2002 arises from the patching together of the past and future components of the scenarios.) Figure 2 shows the globalmean ozone timeseries from CMAM for various altitudes, and Fig. 3 the global-mean temperature timeseries; the results of three ensemble members are shown, each driven by a different sea-surface temperature realization from a coupled atmosphere-ocean model, together with the ensemble mean. The CMAM global-mean ozone and temperature timeseries likewise exhibit strikingly linear behaviour in both past and future, providing some confidence in the basic validity of our linear analysis, presented in Sect. 2. (Note that while the atmospheric temperature response to $\mathrm{CO}_{2}$ increases is not expected to be linear in the troposphere, because of saturation effects, it is expected to be linear in the middle atmosphere (Shine et al., 2003).)

Now in these simulations, $\mathrm{N}_{2} \mathrm{O}, \mathrm{CH}_{4}$ and $\mathrm{H}_{2} \mathrm{O}$ were also increasing with time. Thus there could be some confusion, statistically, between their impact on ozone and temperature and that due to the $\mathrm{CO}_{2}$ increase. $\left(\mathrm{H}_{2} \mathrm{O}\right.$ arguably should be treated as an internal variable rather than a forcing.) In Section 4 it is argued, on the basis of other studies, that these are generally second-order effects in the stratosphere. Nevertheless it is understood that the " $\mathrm{CO}_{2}$ " forcing to be derived below could also represent the chemical and radiative effects of other secularly increasing species.

For both ozone and temperature, the contrast between past and future is different for different altitudes. These differences reflect the different sensitivity to $\mathrm{CO}_{2}$ and ODS changes at different altitudes, and can be exploited as follows to isolate those sensitivities. Based on these figures, we identify two periods of near-linear changes: 1975-1995, during 
(a)

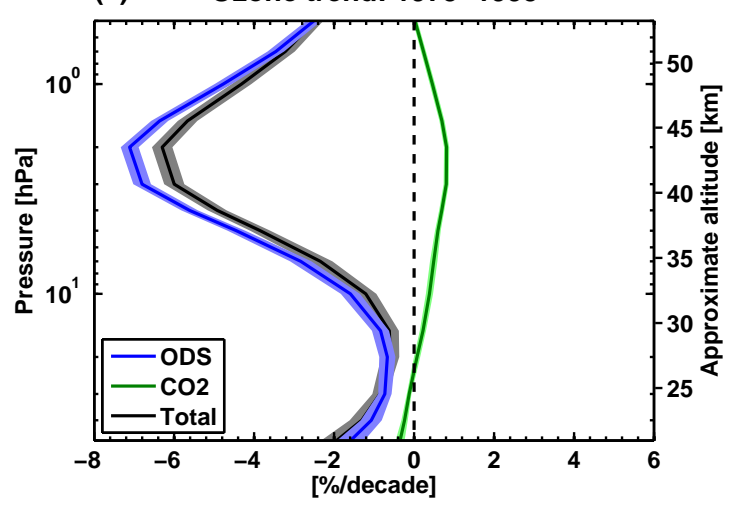

(b)

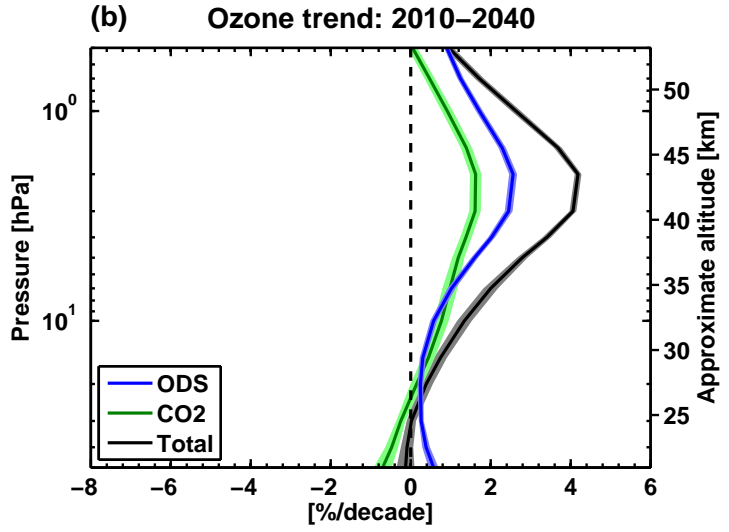

Fig. 4. Attribution of ozone changes over 50-0.5 hPa for the past (1975-1995) and future (2010-2040). The simulated ozone mixing ratio trend (\%/decade) for the selected periods is shown in black while its contributions from $\mathrm{CO}_{2}$ and ODSs are shown in green and blue, respectively. The grey shaded areas indicate the $99 \%$ confidence intervals for the linear fits in Fig. 2. The green and blue shaded regions indicate the uncertainty in the $\mathrm{CO}_{2}$ and ODS attribution estimates, based on error propagation of the $99 \%$ confidence intervals for the fitted $\mathrm{CO}_{2}, \mathrm{Cl}_{\mathrm{y}}$, ozone and temperature linear trends in Figs. 1-3 through Eqs. (17) and (18). The approximate altitudes given on the right-hand side vertical axes are log-pressure heights assuming a constant vertical scale height of $7 \mathrm{~km}$.

the period of ozone depletion, and 2010-2040, during the period of ozone recovery. Because these are long-term changes, we are looking at the change in the steady-state ozone and temperature balances over those periods. We assume that, during each period, the ozone and temperature changes can be entirely explained in terms of the $\mathrm{CO}_{2}$ and ODS changes; thus, we can decompose the past changes (over 1975-1995) according to

$\Delta T^{\mathrm{past}}=\Delta T_{\mathrm{CO}_{2}}^{\mathrm{past}}+\Delta T_{\mathrm{ODS}}^{\mathrm{past}}$,

and the future changes (over 2010-2040) according to

$\Delta T^{\text {future }}=\Delta T_{\mathrm{CO}_{2}}^{\text {future }}+\Delta T_{\mathrm{ODS}}^{\text {future }}=r \Delta T_{\mathrm{CO}_{2}}^{\text {past }}-s \Delta T_{\mathrm{ODS}}^{\text {past }}$,

and similarly for the ozone changes. Here $r$ is the ratio of the $\mathrm{CO}_{2}$ increase over 2010-2040 to that over 1975-1995 (approximately given by 3.0), while $s$ is the ratio of the ODS decrease over 2010-2040 to the increase over 1975-1995 (approximately given by 0.54 ). One can then solve for the past changes attributable to $\mathrm{CO}_{2}$ and ODS changes from (15)(16), i.e.

$\Delta T_{\mathrm{CO}_{2}}^{\text {past }}=\frac{s \Delta T^{\text {past }}+\Delta T^{\text {future }}}{s+r}$

and

$\Delta T_{\mathrm{ODS}}^{\mathrm{past}}=\frac{r \Delta T^{\mathrm{past}}-\Delta T^{\text {future }}}{s+r}$

(and similarly for ozone), where the right-hand sides of (17) and (18) are taken from the simulated changes. (Note that in this empirical approach, all simulated processes are implicitly included in the $\Delta T^{\text {past }}$ and $\Delta T^{\text {future }}$ terms, including for example the effects of heterogeneous chemistry. Limitations in the presented approach are discussed in Sect. 4.)
The future temperature changes attributable to $\mathrm{CO}_{2}$ and ODS changes are given by $r \Delta T_{\mathrm{CO}_{2}}^{\text {past }}$ and $-s \Delta T_{\mathrm{ODS}}^{\text {past }}$, respectively.

The results of these calculations are shown in Fig. 4 for ozone, and Fig. 5 for temperature, expressed in terms of the trend per decade and plotted versus altitude. Although the attribution of temperature and ozone changes to ODSs and $\mathrm{CO}_{2}$ is expected to work best in the upper stratosphere region, the results are shown throughout much of the stratosphere and the lower mesosphere, to enable comparison with other attribution studies (e.g. Shine et al., 2003). Before discussing the attribution results, we first compare the modeled ozone and temperature trends for the past with observations, in order to establish the credibility of the CMAM.

The CMAM ozone trends for the past (Fig. 4a) are in good agreement with the observations. In Chapter 3 of WMO (2007), ozone trends were expressed in terms of \%/decade during the 1980s, when ODSs were increasing linearly with time. Thus, those trends are directly comparable with those presented here. However it must be borne in mind that the CMAM trends are at fixed pressure, while the observed trends may be at fixed pressure (e.g. SBUV(/2)) or fixed altitude (e.g. SAGE); the latter tends to increase the magnitude of the trends in the upper stratosphere. While global-mean trends were not presented in WMO (2007), the observed midlatitude trends are seen to be approximately characteristic of the global mean (Fig. 3-7 of WMO, 2007), and peak (for $\mathrm{SBUV} /(2)$ ) at about $6 \% /$ decade at $2 \mathrm{hPa}$ and $4 \% /$ decade at $100 \mathrm{hPa}$, with a minimum around $20 \mathrm{hPa}$ (Fig. 3-8 of WMO, 2007). These values are very consistent with the CMAM values.

A comparison of the CMAM temperature trends for the past (Fig. 5a) with observations is challenging, because of the significant uncertainty in the vertical profile of past global- 
(a) Temperature trend: $\mathbf{1 9 7 5 - 1 9 9 5}$

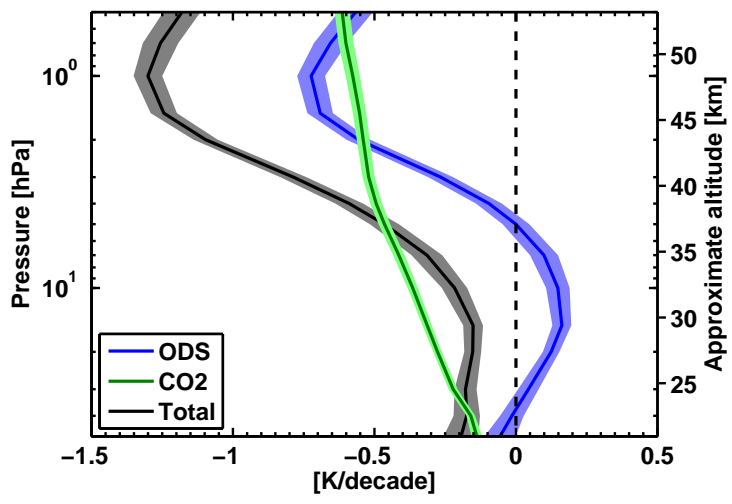

(b) Temperature trend: $\mathbf{2 0 1 0 - 2 0 4 0}$

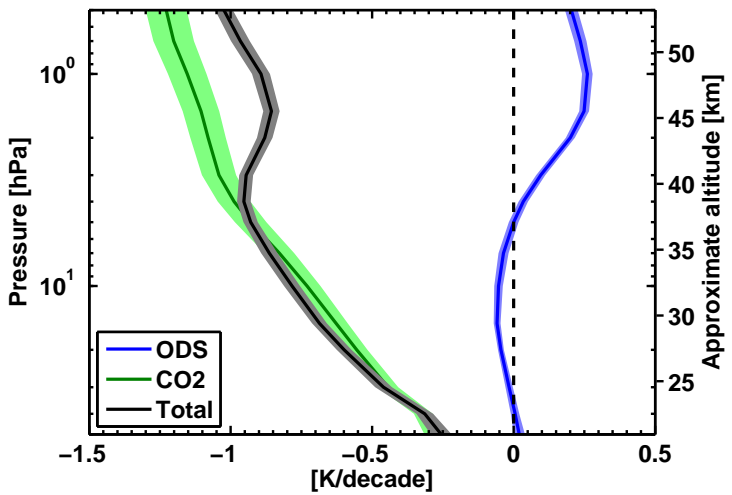

Fig. 5. Same as Fig. 4 but for temperature.

mean stratospheric temperature changes (Chap. 5 of WMO, 2007). Shine et al. (2003) considered both non-interactive models, which had the ozone changes imposed, and interactive chemistry climate models. Both kinds of models gave a vertical profile of the total cooling trend that is quite similar to that exhibited by CMAM, with a principal maximum near $1 \mathrm{hPa}$, a broad minimum around $20 \mathrm{hPa}$, and a weak secondary maximum at about $70 \mathrm{hPa}$. Overall, the magnitude of the CMAM cooling is only about 2/3 as large as the "model mean" of the non-interactive models considered by Shine et al. (2003). However, the individual models show a large range of values. The maximum CMAM cooling of $1.3 \mathrm{~K} /$ decade at $1 \mathrm{hPa}$ is quite consistent with the other chemistry climate models considered by Eyring et al. (2007), as well as with the interactive models considered by Shine et al. (2003). In Chapter 5 of WMO (2007), the model results of Shine et al. (2003), both interactive and non-interactive were considered to be broadly consistent with the observations, given the error bars and other uncertainties, and the agreement has generally improved with the recent revision of the SSU trends (Shine et al., 2008).

We now turn to the issue of attribution. Looking first at the ozone changes (Fig. 4a), the two maxima in the past decreases are both seen to be mainly attributable to ODS changes, although there is a small contribution from $\mathrm{CO}_{2}$ changes at about the $10 \%$ level (i.e. $10 \%$ of the ozone changes are attributable to $\mathrm{CO}_{2}$ rather than ODS changes). In the upper stratosphere, as expected from Sect. 2, the $\mathrm{CO}_{2}$ induced ozone changes have acted to slightly mask the full extent of the ODS-induced ozone decrease, with the difference between the actual and the ODS-attributable globalmean ozone decrease being statistically significant. Nevertheless on the whole the small contribution of $\mathrm{CO}_{2}$ changes to the ozone changes justifies the approach generally taken to attribute past changes (e.g. Chap. 5 of WMO, 2007). Interestingly, in the lower stratosphere the $\mathrm{CO}_{2}$ changes apparently acted to decrease ozone in the past, although in this region the difference between the actual and the ODS-attributable global-mean ozone decrease is not statistically significant.
In contrast, the future ozone changes (Fig. 4b) are significantly affected by $\mathrm{CO}_{2}$ changes, with the upper stratospheric ozone recovery over 2010-2040 coming roughly 3/5 from the decline in ODS abundance and roughly $2 / 5$ from the increase in $\mathrm{CO}_{2}$. This means that the maximum positive trend in ozone at $2 \mathrm{hPa}$ is fully $2 / 3$ of the magnitude of the maximum negative trend over 1975-1995 (i.e. 4\% compared with $6 \%$ ), even though the ODS decline in the future period is much slower than the ODS increase in the past. In the lower stratosphere, the $\mathrm{CO}_{2}$ and ODS effects are seen to largely cancel each other.

Turning now to temperature, the past changes (Fig. 5a) show a $\mathrm{CO}_{2}$-attributable cooling with a smooth vertical profile which, as expected, roughly reflects the profile of temperature itself. However it is notable that the maximum $\mathrm{CO}_{2}$ attributable cooling is only about $0.6 \mathrm{~K} /$ decade, and peaks around $0.5 \mathrm{hPa}$ (not shown), as compared with a maximum $\mathrm{CO}_{2}$-induced cooling of about $0.8 \mathrm{~K} /$ decade peaking closer to $1 \mathrm{hPa}$ for the non-interactive models considered by Shine et al. (2003). The magnitude of this difference is consistent with the magnitude of the ozone-temperature feedback in CMAM (Jonsson et al., 2004) (and, indeed, the interactive models in Shine et al. (2003) gave a substantially smaller maximum cooling than the non-interactive models). The ODS-attributable cooling has two maxima, essentially coincident with the maxima in ODS-attributable ozone loss during the same period (Fig. 4a). Overall, this picture largely confirms the traditional attribution of stratospheric cooling to a combination of $\mathrm{CO}_{2}$ and ODS-induced ozone depletion, since the $\mathrm{CO}_{2}$-induced ozone changes have been a small effect over this time period, although the $\mathrm{CO}_{2}$-induced cooling at the stratopause appears to have been somewhat overestimated.

In contrast, the future temperature changes (Fig. 5b) are dominated by the effects of $\mathrm{CO}_{2}$ changes (both direct, and indirect via ozone). ODS-attributable ozone recovery induces a warming in the vicinity of the stratopause, maximizing at about $0.3 \mathrm{~K} /$ decade around $1 \mathrm{hPa}$, and this leads to a "bite" in the overall cooling profile at the stratopause. This bite is thus 
likely to be the only attributable signature in stratospheric temperature changes of ODS-induced ozone recovery.

\section{Conclusions and discussion}

In this paper we have revisited the traditional approach (e.g. Ramaswamy et al., 2001; Shine et al., 2003) of attributing global-mean stratospheric temperature changes to a combination of $\mathrm{CO}_{2}$ and ozone changes. In light of the strong ozone-temperature coupling that exists in the upper stratosphere (where the stratospheric cooling is the greatest), whereby $\mathrm{CO}_{2}$-induced cooling acts to increase ozone through a reduction in the efficiency of chemical ozone destruction, it is argued that the attribution of temperature changes should be framed instead in terms of changes in $\mathrm{CO}_{2}$ and ozone-depleting substances (ODSs), which are the true anthropogenic forcing agents. Although the differences between $\mathrm{CO}_{2}$-ozone and $\mathrm{CO}_{2}$-ODS attribution can in principle be considerable, an empirical estimation of the importance of ozone-temperature coupling for attribution demonstrated that the differences are not very large when considering changes over the period 1975-1995, when stratospheric ODS abundances were increasing most rapidly. Nevertheless, $\mathrm{CO}_{2}$-induced cooling reduced upper stratospheric ozone depletion by a factor of approximately $10 \%$ over this period, when compared with what would have been expected based on the ODS increases alone. The upper stratospheric cooling due to $\mathrm{CO}_{2}$ has thus been overestimated, and that due to ODS-induced ozone depletion underestimated, in the traditional attribution approach.

However, the problem of identifying stratospheric ozone depletion has recently evolved to that of identifying the onset of ozone recovery, as stratospheric ODS levels begin to slowly decline (see Chap. 6 of WMO, 2007). As the relative importance of ODS changes decreases, the importance of ozone-temperature coupling increases, and it will no longer be viable to retain the traditional $\mathrm{CO}_{2}$-ozone approach to stratospheric temperature attribution. (Or, to be precise, the traditional approach will require further attribution.) Rather, it will become necessary to consider the combined ozonetemperature response to both $\mathrm{CO}_{2}$ and ODS changes, and attempt to separately attribute those changes. In particular, during the expected period of the most rapid ODS decrease, from 2010-2040, it is projected that fully $2 / 5$ of the upper stratospheric ozone increase will be attributable to increases in $\mathrm{CO}_{2}$ rather than to decreases in ODSs. About the only potential signature of ODS-induced ozone recovery in stratospheric temperature will be a "bite" in the profile of stratospheric cooling at the stratopause.

The present analysis has restricted attention to changes in global-mean stratospheric ozone and temperature due to $\mathrm{CO}_{2}$ and ODS changes, as those have been shown to be the primary forcing agents for past changes and are expected to be the dominant agents in ozone recovery (Chaps. 5 and 6 of
WMO, 2007). There are, however, other long-term changes that affect stratospheric ozone and temperature, which warrant some discussion. Whilst the direct contribution of $\mathrm{CH}_{4}$ and $\mathrm{N}_{2} \mathrm{O}$ changes to stratospheric cooling is believed to be small, they could have a more significant effect on ozone chemistry. $\mathrm{N}_{2} \mathrm{O}$ is converted to reactive nitrogen species in the stratosphere which provide the major chemical loss mechanism for ozone. $\mathrm{CH}_{4}$ affects the partitioning of chlorine species but is primarily important as a precursor for water vapour. Water vapour has been much discussed as both a radiative and a chemical forcing agent in the stratosphere (Chap. 1 of IPCC/TEAP, 2005; Chap. 5 of WMO, 2007), although water vapour is not an anthropogenic forcing agent, and any changes in stratospheric water vapour should be considered as an indirect effect of other changes. Water vapour provides the main source of reactive hydrogen oxides that dominate chemical ozone loss in the lower stratosphere and mesosphere. It should be noted that much of the recent attention to the effects of water vapour trends was spurred by balloon and satellite measurements indicating a very large positive trend in stratospheric water vapour in the past, amounting to about $1 \% / y e a r$, which is much stronger than that expected from $\mathrm{CH}_{4}$ increases alone. However, recently it has been shown that this trend is not persistent (Randel et al., 2004).

Within the scope of the present empirical analysis, changes in $\mathrm{CH}_{4}$ and $\mathrm{N}_{2} \mathrm{O}$, as well as any water vapour changes attributable to climate change, are implicitly buried within the " $\mathrm{CO}_{2}$ " term because like $\mathrm{CO}_{2}$ they are also secularly increasing with time over the periods in question. However, it can be argued that their contributions to the stratospheric ozone and temperature changes are generally much smaller than those from changes in ODSs and $\mathrm{CO}_{2}$. Nevison and Holland (1997) have examined the effects of increasing $\mathrm{N}_{2} \mathrm{O}$ on stratospheric ozone in a 2-D model. Applying an $\mathrm{N}_{2} \mathrm{O}$ increase over the 21 st century that is 3-4 times larger than for the $\mathrm{N}_{2} \mathrm{O}$ scenario specified in this work the impact on ozone was limited to about $-1 \% /$ decade, with the maximum effect occurring at $35-40 \mathrm{~km}$. Extrapolating from these results, and taking the differences in $\mathrm{N}_{2} \mathrm{O}$ trends into account, a global mean ozone decrease of up to about $0.33 \% /$ decade could be expected in the CMAM simulations from $\mathrm{N}_{2} \mathrm{O}$ increases, which is much smaller than the ozone trends shown in Fig. 4.

Dvortsov and Solomon (2001) have examined the impact of water vapour increases on temperature and ozone over the period 1979-1996, also using a 2-D model. An imposed linear trend in water vapour of $0.35 \mathrm{ppm} / \mathrm{dec}$ ade (corresponding to a $1 \% /$ year trend) in the tropopause region led to a cooling of the northern hemisphere midlatitude stratosphere of 0.2$0.35 \mathrm{~K} /$ decade (during 1979-1994), partly from the direct radiative effect of water vapour and partly from the imposed effect on chemical ozone loss. As mentioned above, such a strong water vapour increase has recently been shown to be unrealistically large. In the context of the present study, 
the CMAM global mean water vapour increase is only about $0.1 \mathrm{ppm} /$ decade (not shown) over 1975-1995 in the lower stratosphere $(50 \mathrm{hPa})$, and largely attributable to the underlying $\mathrm{CH}_{4}$ trend. Thus, as a rough estimate, up to about $0.1 \mathrm{~K} /$ decade of the past stratospheric temperature response in the CMAM simulation could be expected to be attributable to water vapour changes. For most of the stratospheric temperature attribution (Fig. 5) this is a sufficiently small value not to compromise the analysis. However, for the attribution of lower stratosphere temperature changes in the past the estimated water vapour effect is comparable to the $0.2 \mathrm{~K} / \mathrm{decade}$ cooling calculated by the model in this region (Fig. 3). This means that the presented attribution of past lower stratosphere temperature changes is likely to be skewed so that the part of the temperature change attributed to $\mathrm{CO}_{2}$ is overestimated and the part attributed to ODSs is underestimated. However, for reasons mentioned below, the lower stratosphere results are in any case to be interpreted cautiously. The effects on ozone from past water vapour changes are quite small. Dvortsov and Solomon (2001) show that the additional ozone depletion during 1979-1996 attributable to a $1 \% / y e a r$ water vapour increase is about an order of magnitude smaller than the total trend.

At mesospheric altitudes, the chemical impact of ODSs on ozone decreases with altitude, whereas ozone loss from catalytic cycles involving hydrogen oxides gains in importance. It can therefore be expected that water vapour plays an important role, and that the present attribution technique is at fault in this region. Several studies point out the importance of water vapour changes at the stratopause (e.g. Jucks and Salawitch, 2000; Shindell, 2001), but it should be kept in mind that these generally assume unrealistically large upward trends in water vapour, inconsistent with recent observations (Randel et al., 2004). Nevertheless, results from Shindell (2001) suggest that a significant fraction of past and future temperature trends at $50 \mathrm{~km}$ could be explained by methane driven water vapour increases, which is a fairly well constrained quantity. Thus, the temperature changes attributed to $\mathrm{CO}_{2}$ changes in the mesosphere (Fig. 5) are likely to be overestimated, and likewise, for the ozone attribution (Fig. 4) the apparent reduction in ozone changes attributable to $\mathrm{CO}_{2}$ changes above $45 \mathrm{~km}$ is likely to be at least partly due to increasing water vapour.

In order to identify additional anthropogenic effects beyond those of $\mathrm{CO}_{2}$ and ODSs, it would be necessary to include a third time period (e.g. the second half of the 21st century), or move to a multiple linear regression analysis (R. Stolarski, personal communication, 2007).

The separability of the $\mathrm{CO}_{2}$-ODS attribution advocated here relies on the linearity of the ozone-temperature coupling represented in (1)-(2). For the most part, this is believed to be a good approximation over most of the stratosphere. One obvious way in which such linearity would be violated is through heterogeneous chemistry, where ozone loss would be expected to depend multiplicatively on temperature and
ODSs. Thus, the present approach - or, for that matter, any linear regression analysis - is unlikely to be very reliable in the lowest part of the stratosphere.

Acknowledgements. This research has been supported by the Canadian Foundation for Climate and Atmospheric Sciences.

Edited by: V. Fomichev

\section{References}

de Grandpré, J., Beagley, S. R., Fomichev, V. I., Griffioen, E., McConnell, J. C., Medvedev, A. S. and Shepherd, T. G.: Ozone climatology using interactive chemistry: Results from the Canadian Middle Atmosphere Model, J. Geophys. Res., 105, $26475-$ 26491, 2000.

Dvortsov, V. L., and Solomon, S.: Response of the stratospheric temperatures and ozone to past and future increases in stratospheric humidity, J. Geophys. Res., 106, 7505-7514, 2001.

Eyring, V., Kinnison, D. E., and Shepherd, T. G.: Overview of planned coupled chemistry-climate simulations to support upcoming ozone and climate assessments, SPARC Newsletter, 25, 11-17, 2005.

Eyring, V., Waugh, D. W., Bodeker, G. E., et al.: Multi-model projections of stratospheric ozone in the 21st century, J. Geophys. Res., 112, D16303, doi:10.1029/2006JD008332, 2007.

Fomichev, V. I., Ward, W. E., Beagley, S. R., McLandress, C., McConnell, J. C., McFarlane, N. A., and Shepherd, T. G.: The extended Canadian Middle Atmosphere Model: Zonal-mean climatology and physical parameterizations, J. Geophys. Res., 107, 4087, doi:10.1029/2001JD000479, 2002.

Haigh, J. D. and Pyle, J. A.: Ozone perturbation in a twodimensional circulation model, Q. J. Roy. Meteor. Soc., 108, 551-574, 1982.

IPCC/TEAP (Inter-Governmental Panel on Climate Change/Technology and Economic Assessment Panel): IPCC/TEAP Special Report on Safeguarding the Ozone Layer and the Global Climate System: Issues Related to Hydrofluorocarbons and Perfluorocarbons, Cambridge University Press, 488 pp., 2005.

Jonsson, A. I., de Grandpré, J., Fomichev, V. I., McConnell, J. C., and Beagley, S. R.: Doubled $\mathrm{CO}_{2}$-induced cooling in the middle atmosphere: Photochemical analysis of the ozone radiative feedback, J. Geophys. Res., 109, D24103, doi:10.1029/2004JD005093, 2004.

Jucks, K. W. and Salawitch, R. J.: Future changes in upper stratospheric ozone, in: Atmospheric Science Across the Stratopause, edited by: Siskind, D. E., Eckermann, S. D., and Summers, M. E., Geophysical Monograph Series, No. 123, American Geophysical Union, 241-255, 2000.

Nevison, C., and Holland, E.: A reexamination of the impact of anthropogenically fixed nitrogen on atmospheric $\mathrm{N}_{2} \mathrm{O}$ and the stratospheric $\mathrm{O}_{3}$ layer, J. Geophys. Res., 102, 25 519-25 536, 1997.

Ramaswamy, V., Chanin, M.-L., Angell, J., et al.: Stratospheric temperature trends: Observations and model simulations, Rev. Geophys., 39, 71-122, 2001.

Randel, W. J., Wu, F., Oltmans, S., Rosenlof K., and Nedoluha, G.: Interannual changes of stratospheric water vapor and correlations 
with tropical tropopause temperatures, J. Atmos. Sci., 61, 21332148, 2004.

Shindell, D. T.: Climate and ozone response to increased stratospheric water vapor, Geophys. Res. Lett., 28, 1551-1554, 2001.

Shine, K. P., Bourqui, M. S., Forster, P. M., et al.: A comparison of model-simulated trends in stratospheric temperatures, Q. J. Roy. Meteor. Soc., 129, 1565-1588, 2003.
Shine, K. P., Barnett, J. J., and Randel, W. J.: Temperature trends derived from Stratospheric Sounding Unit radiances: The effect of increasing $\mathrm{CO}_{2}$ on the weighting function, Geophys. Res. Lett., 35, L02710, doi:10.1029/2007GL032218, 2008.

WMO (World Meteorological Organization): Scientific Assessment of Ozone Depletion: 2006, Global Ozone Research and Monitoring Project-Report, No. 50, Geneva, Switzerland, 572 pp., 2007. 